\title{
Photoacclimatization by the coral Montastraea cavernosa in the mesophotic zone: light, food, and genetics
}

\author{
Michael P. Lesser,${ }^{1,5}$ Marc Slattery, ${ }^{2}$ Michael Stat,${ }^{3}$ Michiko Ojimi,${ }^{3}$ Ruth D. Gates,${ }^{3}$ \\ AND Andrea Grottoli ${ }^{4}$ \\ ${ }^{1}$ Department of Molecular, Cellular and Biomedical Sciences, University of New Hampshire, Durham, New Hampshire 03824 USA \\ ${ }^{2}$ Department of Pharmacognosy, University of Mississippi, University, Mississippi 38677 USA \\ ${ }^{3}$ Hawaii Institute for Marine Biology, University of Hawaii, Kaneohe Bay, Hawaii 96744 USA \\ ${ }^{4}$ Ohio State University, School of Earth Sciences, 125 South Oval Mall, Columbus, Ohio 43210 USA
}

\begin{abstract}
Most studies on coral reefs have focused on shallow reef $(<30 \mathrm{~m})$ systems due to the technical limitations of conducting scientific diving deeper than $30 \mathrm{~m}$. Compared to their shallow-water counterparts, these mesophotic coral reefs $(30-150 \mathrm{~m})$ are understudied, which has slowed our broader understanding of the biodiversity, ecology, and connectivity of shallow and deep coral reef communities. We know that the light environment is an important component of the productivity, physiology, and ecology of corals, and it restricts the distribution of most species of coral to depths of $60 \mathrm{~m}$ or less. In the Bahamas, the coral Montastraea cavernosa has a wide depth distribution, and it is one of the most numerous corals at mesophotic depths. Using a range of optical, physiological, and biochemical approaches, the relative dependence on autotrophy vs. heterotrophy was assessed for this coral from 3 to $91 \mathrm{~m}$. These measurements show that the quantum yield of PSII fluorescence increases significantly with depth for $M$. cavernosa while gross primary productivity decreases with depth. Both morphological and physiological photoacclimatization occurs to a depth of $91 \mathrm{~m}$, and stable isotope data of the host tissues, symbionts, and skeleton reveal a marked decrease in productivity and a sharp transition to heterotrophy between 45 and $61 \mathrm{~m}$. Below these depths, significant changes in the genetic composition of the zooxanthellae community, including genotypes not previously observed, occur and suggest that there is strong selection for zooxanthellae that are suited for survival in the light-limited environment where mesophotic $M$. cavernosa are occurring.
\end{abstract}

Key words: corals; fluorescence; mesophotic zone; Montastraea cavernosa; productivity; stable isotopes.

\section{INTRODUCTION}

Caribbean-wide declines of shallow-water scleractinian corals are most closely linked to the collapse of an important herbivore, the sea urchin Diadema antillarum, and subsequent phase transitions to algaldominated reefs, increasing incidence of coral disease, recurring sources of disturbance such as hurricanes, and coral bleaching related to thermal stress (Gardner et al. 2003, Hughes et al. 2003, Lesser 2004). The loss of ecological services that these shallow coral reefs provide (i.e., tourism, fisheries, shoreline protection) significantly diminishes the economy and survival of many countries (Moberg and Folke 1999). Deep fore-reef coral reefs $(>30 \mathrm{~m})$, however, are believed to be largely free from human-mediated stresses and natural impacts due to their increased distance from human populations and their greater depth than adjoining shallow-water coral reefs (Riegl and Piller 2003). Recent long-term studies over 30 years have shown that reefs at these

Manuscript received 30 March 2009; revised 2 July 2009; accepted 13 July 2009. Corresponding Editor: R. B. Aronson.

${ }^{5}$ E-mail: mpl@unh.edu depths change little in percent cover or species composition (Bak et al. 2005).

The renewed interest in deep fore-reef communities occurs at a time when shallow reefs are undergoing unprecedented changes (Jackson 2008), and the potential for these communities to serve as refugia for critical taxa such as fish and corals, as well as sources/sinks for shallow-water coral populations, is increasingly of interest to both coral reef ecologists and managers (Reigel and Piller 2003). These deep fore-reef communities have recently been renamed mesophotic coral ecosystems $(30-150 \mathrm{~m})$ to distinguish them from deep, cold, scleractinian coral reefs. Mesophotic reefs are defined as deep fore-reef communities occurring in low light habitats and composed of light-dependent zooxanthellate scleractinian corals, azooxanthellate scleractinian corals, macroalgae, and sponge-dominated communities (Lesser et al. 2009). The number of ecological studies on these deep reefs is significantly less than studies on shallow-water coral reefs (Menza et al. 2008), and our current knowledge of benthic community structure on many deep fore-reefs consists of a small number of largely descriptive reports using submersibles, remotely operated vehicles, or SCUBA (Goreau 
and Wells 1967, Kühlmann 1983, Fricke and Meischner 1985, Fricke and Knauer 1986, Liddell et al. 1997, Lehnert and Fischer 1999, Jarrett et al. 2005, Grigg 2006). However, in a comprehensive study of coral reefs in the Bahamas, Liddell et al. (1997) reported on the percent cover and species diversity of reef communities down to a depth of $250 \mathrm{~m}$ using both SCUBA and submersibles. Their study showed a distinct bathymetric zonation pattern with coral cover of 3-23\% at depths shallower than $50 \mathrm{~m}$ and subsequent decreases in coral cover with increasing depths. In contrast, the percent cover of sponges increased with increasing depth in the same study. Liddell et al. (1997) reported that the decrease in irradiance with increasing depth and substrate stability were the two most important factors affecting the community structure of these deep reef systems. Recent studies on the photophysiology of mesophotic corals (Mass et al. 2007), the ecological distributions of mesophotic corals (Kahng and Kelley 2007), and the biophysical coupling of coral growth in mesophotic environments with internal waves or upwelling events (Leichter and Genovese 2006) were all accomplished using technical diving.

Changes in solar radiation with increasing depth, both irradiance and spectral quality, is the primary abiotic factor affecting the productivity and distribution of benthic photosynthetic organisms (Gattuso et al. 2006), and zooxanthellate corals in particular (Dustan 1982, Wyman et al. 1987, Falkowski et al. 1990, Frade et al. $2008 a$ ). In addition to changes in the bulk underwater light environment, there are smaller scale differences in the light environment along the deep fore reef that can affect zooxanthellate coral distributions (Vermeij and Bak 2002). There are fewer studies on the photophysiology of corals from mesophotic habitats but the available work shows significant photoacclimatization to decreasing irradiance (e.g., Wyman et al. 1987). As part of the photoacclimatization process, the photosynthetic machinery is reorganized to maximize light collection and may involve the expression of novel host-associated accessory pigments (e.g., fluorescent pigments), changes in coral morphology, and replacement of genetically distinct zooxanthellae along micro- and macro-gradients of light (Schlichter et al. 1986, Wyman et al. 1987, Falkowski et al. 1990, Sampayo et al. 2007, Frade et al. 2008b, Todd 2008).

On coral reefs in the Caribbean basin, only a few species of scleractinian coral span the shallow and mesophotic depth range of $\sim 3-100 \mathrm{~m}$ (Reed 1985). One of these is Montastraea cavernosa, a broadcast spawner, and a species known to be highly tolerant of elevated seawater temperatures (Fitt and Warner 1995). Additionally, colonies of $M$. cavernosa exhibit significant phenotypic variation in morphology (see Plate 1) and rates of respiration over its bathymetric range of occurrence (Davies 1980, Lasker 1981). It also has the capability to absorb and utilize low irradiances of light efficiently (Wyman et al. 1987, Lesser et al. 2000). Here we use several approaches to understand the physiological ecology of $M$. cavernosa, including bio-optics, photophysiology, stable isotopes, and molecular genetics to specifically address the transition from autotrophy to heterotrophy in $M$. cavernosa as light becomes a limiting factor.

\section{Materials And Methods}

\section{Study site}

All research described here was conducted at Lee Stocking Island, Bahamas $\left(23^{\circ} 46.5^{\prime} \mathrm{N}, 76^{\circ} 5.5^{\prime} \mathrm{W}\right)$. Significant deep fore-reef coral communities with adjoining shallow-water coral reefs are found at this location, and replicate samples $(n=5)$ of Montastraea cavernosa (Linnaeus) were collected at the following depths; 3, 9, 18, 23, 30, 45, 61, 76, and 91 m using opencircuit SCUBA (i.e., air, deep air, NITROX, deep NITROX, and TRIMIX protocols). Samples were transported back to the laboratory in the dark and placed in flow-through seawater aquaria with neutral density screens to maintain samples at irradiances $<25$ $\mu \mathrm{mol}$ quanta $\cdot \mathrm{m}^{-2} \cdot \mathrm{s}^{-1}$. M. cavernosa can exhibit morphological differences over its range of occurrence (Amaral 1994), and therefore only samples corresponding to the "nocturnal morph," as described by Lasker (1981), were collected for analysis. However, mitochondrial and nuclear gene phylogenies for samples of $M$. cavernosa of varying morphology from different sites and depths show no species-level divergence (Billinghurst et al. 1997, Snell et al. 1998).

\section{Field measurements}

Profiles of water column properties were taken over several cloudless $(<10 \%$ cloud cover) days at midday (12:00-13:00 hours) using a Seabird 19 CTD (salinity [PSU] and temperature $\left[\mathrm{C}^{\circ}\right]$; Sea-Bird Electronics, Bellevue, Washington, USA) fitted with a calibrated fluorometer to measure chlorophyll $a(\mu \mathrm{g} / \mathrm{L})$, and a light meter fitted with a $4 \pi$ collector that measured integrated scalar irradiance of photosynthetically active radiation $(\mathrm{PAR}=400-700 \mathrm{~nm})$. All instruments were calibrated to manufacturers' specifications. Vertical attenuation coefficients for downwelling irradiance of PAR $\left(\mathrm{K}_{\mathrm{dPAR}} / \mathrm{m}\right)$ and the optical depths for $1 \%$ and $10 \%$ irradiances were calculated as described by Kirk (1994).

$M$. cavernosa colonies were counted along replicate $25 \times 1 \mathrm{~m}$ transects at depths of $23 \mathrm{~m}(n=4), 46 \mathrm{~m}(n=$ 4), $69 \mathrm{~m}(n=3)$, and $92 \mathrm{~m}(n=2)$ near Lee Stocking Island, Bahamas. The morphology of each M. cavernosa colony (i.e., upright vs. plating) encountered along these transects was assessed as a function of percent cover. A $1-\mathrm{m}^{2}$ quadrat, subdivided with twine into 16 equal squares, was used to determine the relative size of each coral colony.

Samples of seawater $(n=3)$ were collected in large $(60$ $\mathrm{mL}$ ) syringes at each depth $\sim 1 \mathrm{~m}$ from the substrate at all depths. The samples were brought to the surface, transported in the dark, and fixed in filtered $(0.2-\mu \mathrm{m}$ 
filter) seawater, at a final concentration of $0.5 \%$ in electron microscopy-grade glutaraldehyde, and shipped frozen at $-80^{\circ} \mathrm{C}$. Samples were sent frozen to the Bigelow Laboratory for Ocean Sciences Flow Cytometry Facility, West Boothbay Harbor, Maine, USA, where they were stored in liquid nitrogen until analysis as described by Lesser et al. (1992). Each sample was analyzed for cell abundances using a Becton Dickinson FACScan flow cytometer (Franklin Lakes, New Jersey, USA) equipped with a 15-mW, 488-nm, air-cooled Argon ion laser. Simultaneous measurements of forward light scatter (FSC, relative size), $90^{\circ}$ degree light scatter (SSC), chlorophyll fluorescence $(>650 \mathrm{~nm})$, and phycoerythrin fluorescence $(560-590 \mathrm{~nm})$ were made on all samples. Food availability was categorized into total phytoplankton, eukaryotic phytoplankton, and cyanobacteria (Synechococcus sp.).

\section{Laboratory analyses}

For each replicate coral, a plug $\left(1.8-1.95 \mathrm{~cm}^{2}\right)$ was obtained using a drill and hole saw under a constant stream of seawater. Each plug was analyzed for chlorophyll $a$ by placing it in $50-\mathrm{mL}$ conical tubes overnight in $10 \mathrm{~mL}$ of $90 \%$ acetone at $4^{\circ} \mathrm{C}$. Subsequent$1 \mathrm{y}$, the extracted pigments were centrifuged $(\times 1000 \mathrm{~g})$ to remove particulate material, and the absorbance was measured against acetone blanks at $630 \mathrm{~nm}$ and $663 \mathrm{~nm}$. The trichromatic equations of Jeffrey and Humphrey (1975) were then used to calculate the concentrations of chlorophyll $a$ and $c_{2}$. Additional plugs were taken as described, and each was airbrushed $(80 \mathrm{psi},<1 \mathrm{~cm}$ distance to coral) with a small volume $(5 \mathrm{~mL})$ of filtered (0.22-mm filter) seawater to remove coral tissues. Replicate aliquots $(n=3)$ were taken from each homogenate and fixed with Lugol's iodine for enumeration ( $n=3$ counts per sample and averaged) using a Neubauer hemocytometer and light microscopy. Chlorophyll $a$ and $c_{2}$ were expressed on an aerial and per cell basis, and chlorophyll $a: c_{2}$ ratios were calculated.

Active fluorescence was measured on dark-acclimated samples $(n=3)$ using a pulse amplitude modulated (PAM) fluorometer (Walz, Effeltrich, Germany). All measurements were taken at the same distance and probe angle for both hemispherical and plating morphologies. Measurements of minimum $\left(F_{0}\right)$ and maximum $\left(F_{\mathrm{m}}\right)$ fluorescence are used to calculate variable $\left(F_{\mathrm{v}}=F_{\mathrm{m}}-F_{0}\right)$ fluorescence and subsequently the maximum quantum yield of photosystem II (PSII) fluorescence $\left(F_{\mathrm{v}} / F_{\mathrm{m}}\right)$ or the number of functional photosynthetic units. The housing of the diver-operated PAM fluorometer is only rated to a maximum depth of $50 \mathrm{~m}$ so measurements of steady state quantum yields $\left(\Delta F_{\mathrm{v}} / F_{\mathrm{m}}^{\prime}\right)$ in the field were not undertaken. In addition, each coral was also assessed for the electron transport rate (ETR) through PSII at different irradiances using the rapid light curve (RLC) protocol of the PAM instrument. Each RLC exposed the coral to eight incremental steps of irradiance from 0 to $300 \mu \mathrm{mol}$ quanta $\cdot \mathrm{m}^{-2} \cdot \mathrm{s}^{-1}$. This lower range of irradiances was used on corals from all depths so as not to induce photoinhibition in corals from deeper depths. The ETR at each irradiance was calculated using the formula ETR $=F_{\mathrm{v}} / F_{\mathrm{m}} \times \mathrm{PAR} \times A \times 0.5$, where the quantum yield is the quantum yield measured at each irradiance of PAR from the internal halogen bulbs, $A$ is the absorbance of each coral averaged across all PAR wavelengths (see next paragraph), and 0.5 is the theoretical distribution of absorbed photons between PSII and photosystem I (PSI). The resulting RLC curves were then fitted using nonlinear regression to estimate the maximum ETR $\left(\mathrm{ETR}_{\max }\right)$ for corals at each depth, as described by Platt et al. (1980), for estimating maximum photosynthesis $\left(P_{\max }\right)$ from photosynthesis-irradiance curves (see Lesser 1996).

A calculation of gross primary productivity (GPP) was made on corals from each depth by taking an optical approach similar to previously described approaches on corals (Wyman et al. 1987, Lesser et al. 2000) and coral reefs using remote sensing (Hochberg and Atkinson 2008). The optical-based model is simply described as GPP $=E_{\mathrm{d}} \times A \times \phi_{\mathrm{m}}$, where downwelling irradiance $\left(E_{\mathrm{d}}\right)$ represents the irradiance incident at each depth in quanta, absorbance $(A)$ describes the fractional amount of light absorbed by each coral (nondimensional), and $\phi_{\mathrm{m}}$ is the maximum quantum yield for photosynthesis or the amount of $\mathrm{O}_{2}$ evolved per quanta absorbed. $E_{\mathrm{d}}$ is obtained from the profiles of midday irradiances of PAR described above; $A$ is obtained from inverting the spectral reflectance $(R)$ for each coral $(R[\lambda]=1-A[\lambda])$ and averaged across all visible wavelengths $(400-700 \mathrm{~nm})$. The spectral reflectance was obtained from each coral as described in Mazel et al. (2003). The available $\phi_{\mathrm{m}}$ data for $M$. cavernosa (Wyman et al. 1987, Lesser et al. 2000) from 1 to $50 \mathrm{~m}$ were regressed against the depth of occurrence, and fitted values for all depths were then used in the calculation of GPP at each depth for each coral. Because of the instantaneous nature of the $E_{\mathrm{d}}$ measurements, GPP was expressed as $\mathrm{mol} \mathrm{O}_{2} \cdot \mathrm{m}^{-2} \cdot \mathrm{d}^{-1}$. To look at the relationship between $\mathrm{ETR}_{\max }$ and GPP, we regressed the two variables using a type II model linear regression (LaBarbera 1989) and analysis of variance (ANOVA), since both variables contain measurement error.

Replicate samples $(n=4-5)$ of $M$. cavernosa had their host and symbiont tissue removed using a Water-pik (Fort Collins, Colorado, USA) for stable isotope analyses. These fractions were then separated by centrifugation ( $5 \mathrm{~min}$ at $5000 \mathrm{~g}$ ). The host fraction was isolated onto pre-burned glass fiber filters and the zooxanthellae fraction was acidified to remove skeletal fragments and then isolated on glass fiber filters for the analysis of $\delta^{15} \mathrm{~N}$ and $\delta^{13} \mathrm{C}$. Skeletal material was prepared for $\delta^{13} \mathrm{C}$ and $\delta^{18} \mathrm{O}$ analysis as described by Rodrigues and Grottoli (2006). Briefly, zooxanthellae and host tissue filters were individually combusted with a Costech Elemental Analyzer (Valencia, California, 
USA) coupled to a Finnigan Delta IV stable isotope ratio mass spectrometer (SIR-MS; Thermo Scientific, Waltham, Massachusetts, USA) via a Conflow III interface (Conflow Technologies, Brampton, Ontario, Canada) for the analysis of $\delta^{15} \mathrm{~N}$ and $\delta^{13} \mathrm{C}$ using air and Vienna Peedee belemnite limestone (VPDB) as standards. For the skeletal material, a 75-95 $\mu \mathrm{g}$ subsample was analyzed for $\delta^{13} \mathrm{C}$ and $\delta^{18} \mathrm{O}$ using VPDB as standards in an automated Carbonate Kiel device coupled to the SIR-MS. All values are expressed on a per-mil (\%) basis which is the variation of the stable isotope being measured relative to the standard. Estimates of the ratio of photosynthesis/respiration $(\mathrm{P} / \mathrm{R})$, a measure of the dependence on autotrophy vs. heterotrophy, were made using the stable oxygen and carbon isotopes of the skeletal, animal, and zooxanthellae compartments as described by Heikoop et al. (2000). There was insufficient material for any analysis of $76 \mathrm{~m}$ samples for $\delta^{13} \mathrm{C}$ and $\delta^{15} \mathrm{~N}$ and for $\delta^{15} \mathrm{~N}$ from $91 \mathrm{~m}$.

Zooxanthellae from the corals collected were isolated using a protocol described by Lesser and Farrell (2004). DNA from the zooxanthellae was isolated using a modified protocol with the DNeasy Plant Mini Kit (Qiagen, Valencia, California, USA). For PCR amplification, a portion of the 5.8S, ITS2, and part of the $28 \mathrm{~S}$ rDNA was amplified using the primers "ITSintfor2" (LaJeunesse 2002) and "ITS2rev" (lacks the GC clamp, otherwise identical to "ITS2CLAMP"; LaJeunesse 2002), and a touchdown PCR protocol with annealing conditions of $62-52^{\circ} \mathrm{C}$ and decreasing $0.5^{\circ} \mathrm{C}$ every cycle, with 12 cycles held at the final annealing temperature of $52^{\circ} \mathrm{C}$. PCR amplicons were purified using the QIAquick ${ }^{\circledR}$ PCR Purification Kit (Qiagen), ligated into the pGEM-T Easy vector (Promega, Madison, Wisconsin, USA), transformed into $\alpha$-select gold efficiency competent cells (Bioline, Taunton, Massachusetts, USA), and grown overnight in Circlegrow (MP Biomedicals, Solon, Ohio, USA). Plasmids were purified using the Perfectprep Plasmid Isolation Kit (Eppendorf, Hamburg, Germany), and each product cycle-sequenced using BigDye Terminators (PerkinElmer, Waltham, Massachusetts, USA) on an ABI-3100 automated sequencer (Applied Biosystems, Foster City, California, USA) at the University of Hawaii at Manoa. Ambiguous sequence reads were confirmed by alignment to the reverse complement.

Sequences were aligned and manually edited using the software MacVector v. 8.0.2 (2005; MacVector, Cary, North Carolina, USA). A conservative approach for the acceptance of a Symbiodinium ITS2 sequence was further employed. That is, to be included for downstream analysis, a sequence must either have been previously published or must have occurred in multiple clone libraries originating from different corals and developed from independent PCR reactions. Nucleotide changes that could not be confirmed were edited back to the consensus base for that particular nucleotide position. In all cases where this was necessary, the position was conserved making this an unambiguous choice. IT2S folding was conducted using previously published Symbiodinium ITS2 structures as templates (Hunter et al. 2007, Thornhill et al. 2007) in the ITS2 database (Schultz et al. 2006, Selig et al. 2008) and manually edited using the software 4SALE (Seibel et al. 2006, 2008). Potential pseudogenes were characterized by significant changes to the $5.8 \mathrm{~S}$ sequence not observed in Symbiodinium or other closely related dinoflagellates (Thornhill et al. 2007) and changes to the secondary structure of the ITS2 RNA molecule that likely disrupt the functional fold. Pseudogenes were included in downstream analysis representing the closest putative functional ITS2 sequence (the sequence it likely originates from). Sequences were deposited in GenBank (FJ793504-FJ793514).

\section{Data analyses}

These data constitute a "natural experiment," with depth as a fixed factor, and are amenable to parametric analysis such as ANOVA. No unequal variances were detected using the $F_{\max }$ test, and when significant treatment effects were detected, individual treatment differences were assessed using the Student-NewmanKeuls (SNK) multiple comparison test. Where appropriate, ratios and percentages were arcsine or log transformed for analysis and back transformed for presentation purposes.

The software package PRIMER v.6 (Clarke and Warwick 2001) was used for a comparison of the Symbiodinium ITS2 community signature harbored by shallow-water $(0-46 \mathrm{~m})$ and deep-water $(>60 \mathrm{~m})$ corals. These two depth groupings were selected based on the transition of autotrophy to heterotrophy (see Results). Relative abundances of each ITS2 sequence in each coral colony were arranged in a matrix and transformed by taking the square root of each value (which adds more weight to low-frequency sequences in the data set) and compared using the Bray-Curtis coefficient of similarity ( $S$; Bray and Curtis 1957). Bray-Curtis similarities were visualized using two-dimensional nonmetric multidimensional scaling (MDS). A one-way analysis of similarity (ANOSIM) was calculated in PRIMER to detect significant differences in the Symbiodinium ITS2 sequence signature between depths. The test statistic $(R)$ in ANOSIM ranges between +1 and -1 , where a value 0 indicates no differences between groups, approaching +1 indicates partitioning of variation by group, and approaching -1 indicates partitioning of variation within group is greater than between groups. Furthermore, the SIMPER test was used to determine the Symbiodinium sequence that contributed to the dissimilarity between the two groupings.

\section{RESUlts}

Daily midday vertical profiles of photosynthetically active radiation (PAR) on cloudless days $(n=3)$ showed little variability $( \pm 5-10 \%)$ during the experimental 

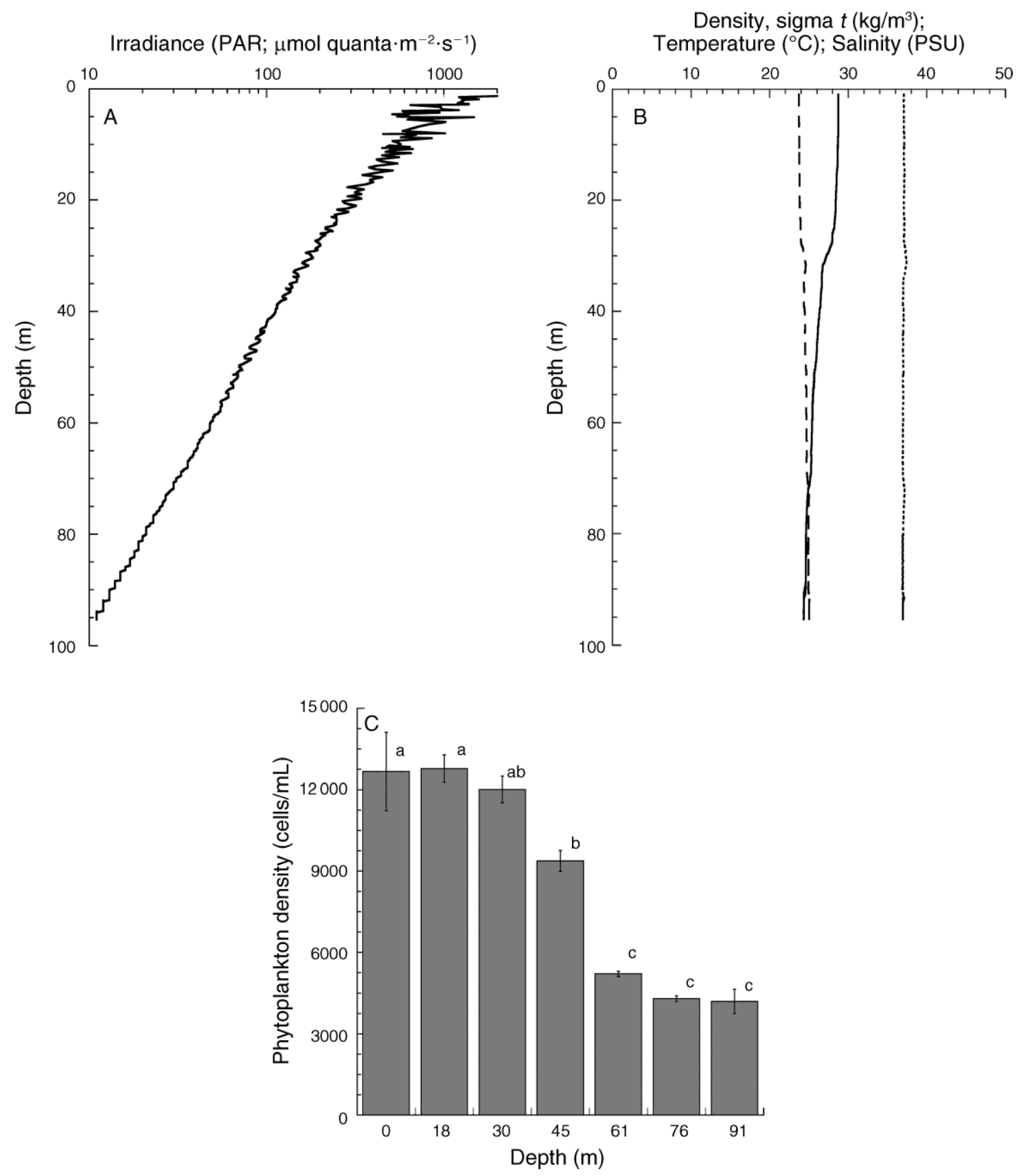

FIG. 1. (A) Continuous measurement of downwelling irradiance $\left(E_{\mathrm{d}}\right)$ with depth from just below the surface to $95 \mathrm{~m}$ depth. Surface irradiance was $2478 \mu \mathrm{mol}$ quanta $\cdot \mathrm{m}^{-2} \cdot \mathrm{s}^{-1}$ while the irradiance at $95 \mathrm{~m}$ depth was $11 \mu \mathrm{mol}$ quanta $\cdot \mathrm{m}^{-2} \cdot \mathrm{s}^{-1}$. Note that the $x$ axis is a $\log$ scale. (B) Continuous measurement of temperature, salinity, and density with depth from just below the surface to $95 \mathrm{~m}$ depth. Temperature is the solid line, salinity is the small dotted line, and sigma $t$ is the dashed line. (C) Total phytoplankton (eukaryotic plankton and cyanobacteria), measured using flow cytometry, available from the surface to $91 \mathrm{~m}$ depth. Different lowercase letters indicate those depths significantly different from one another using post hoc Student-Newman-Keuls [SNK] multiple comparison tests $(P<0.05)$. All profiles and discrete measurements are from Bock Wall, Lee Stocking Island, Bahamas.

period, suggesting that the optical properties of the water column changed very little during this time period. A typical vertical profile of PAR from the surface to $>90 \mathrm{~m}$ has a maximum surface PAR irradiance of 2478 $\mu$ mol quanta $\cdot \mathrm{m}^{-2} \cdot \mathrm{s}^{-1}$ (Fig. 1A). The mean downwelling irradiance of PAR $\left(K_{\mathrm{dPAR}}\right)$ for the water column around
Lee Stocking Island, Bahamas was $0.057 \mathrm{~m}^{-1}( \pm 0.006$ $\mathrm{m}^{-1} \mathrm{SE}$ ) with the $10 \%$ optical depth (midpoint of euphotic zone) occurring at $40 \mathrm{~m} \quad(112 \mu \mathrm{mol}$ quanta. $\mathrm{m}^{-2} \cdot \mathrm{s}^{-1}$ ) and the $1 \%$ optical depth (compensation depth or bottom of euphotic zone) occurring at 81 $\mathrm{m}\left(21 \mu \mathrm{mol}\right.$ quanta $\left.\cdot \mathrm{m}^{-2} \cdot \mathrm{s}^{-1}\right)$. Vertical profiles (Fig. 1B) 


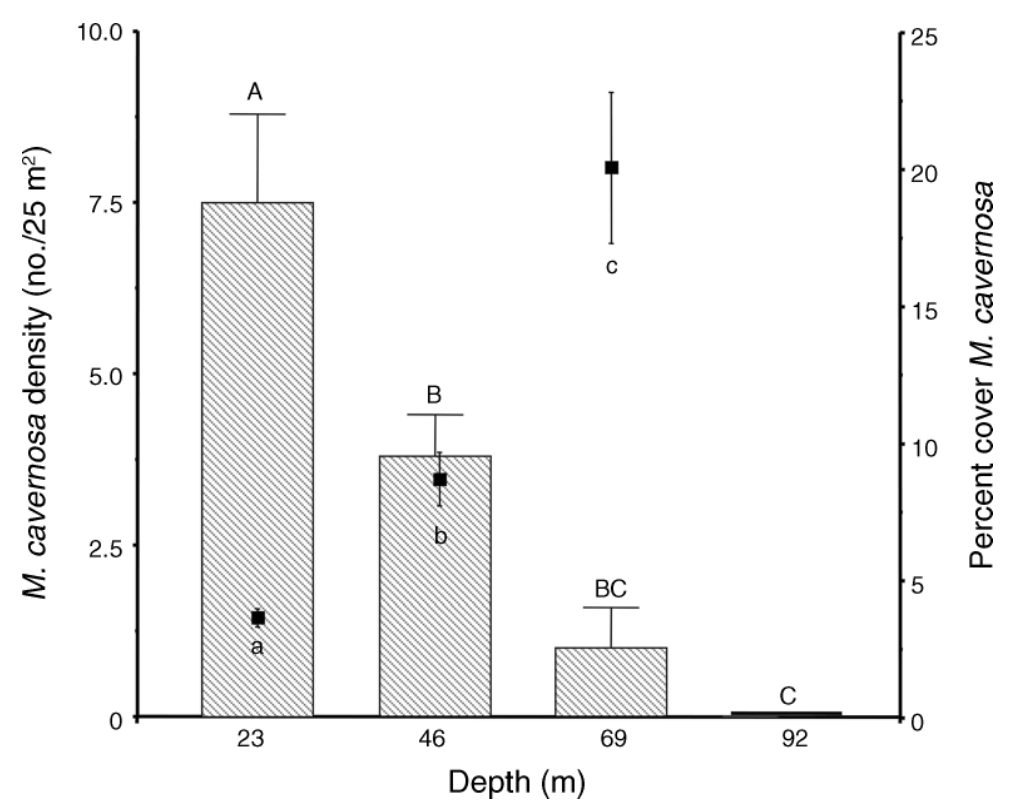

FIG. 2. Change in density of the coral Montastraea cavernosa (bars and capital letters) with depth compared to the percent cover (solid boxes and lowercase letters) of the same samples. Error bars represent standard error. Both the change in numbers and percent cover with depth were significant and inversely correlated. Different letters above each depth indicate depths significantly different from one another using post hoc multiple comparison testing (SNK tests; $P<0.05$ ).

of salinity, temperature, and density showed a generally well-mixed water column down to at least $90 \mathrm{~m}$ with little change in salinity and density, and variations in temperature from values of $28-29^{\circ} \mathrm{C}$ at the surface to $24-25^{\circ} \mathrm{C}$ at $90 \mathrm{~m}$. Total phytoplankton (eukaryotic phytoplankton and Synechococcus sp.) decreased significantly with depth (ANOVA, $F_{6,14}=37.89, P<0.0001$; Fig. 1C). Post hoc multiple comparison testing (SNK) showed significant (SNK, $P<0.05$ ) breaks in the depth distribution of total phytoplankton between surface to $30 \mathrm{~m}, 30-45 \mathrm{~m}$, and 61-91 m (Fig. 1C) with the larger eukaryotic phytoplankton composing from $8 \%$ to $14 \%$ of the total phytoplankton biomass.

The number of Montastraea cavernosa exhibited a significant decrease with depth (Fig. 2). Coral colony numbers were highest at $23 \mathrm{~m}\left(7.5 \pm 1.3\right.$ per $25 \mathrm{~m}^{2}$; mean $\pm \mathrm{SE}$ for all data shown), and lowest at $92 \mathrm{~m}(0$ per $25 \mathrm{~m}^{2}$ ) (ANOVA, $F_{3,9}=11.57, P=0.002$ ). An inverse relationship was noted for percent cover of $M$. cavernosa; the coral colonies exhibited significantly greater percent cover due to their plating morphology (Fig. 2). Although only three colonies were assessed at $69 \mathrm{~m}$, the percent cover averaged $19.8 \% \pm 2.8 \%$, in contrast to a mean cover of $8.4 \% \pm 1.0 \%$ at $46 \mathrm{~m}(n=15$ colonies) and $3.4 \% \pm 0.3 \%$ at $23 \mathrm{~m}(n=30$ colonies $)$ (ANOVA, $\left.F_{2,45}=56.74 ; P<0.0001\right)$.

For corals collected from 3 to $91 \mathrm{~m}$, the photosynthetic pigment increased significantly with depth. Total chlorophyll ( $a$ plus $c_{2}$ ) $/ \mathrm{cm}^{2}$ increased significantly with depth (ANOVA, $F_{8,18}=20.04, P<0.0001$; Fig. 3A), as did total chlorophyll/cell (ANOVA, $F_{8,18}=52.28, P<$ 0.0001 ; Fig. 3A) and the chlorophyll $a: c_{2}$ ratio
(ANOVA, $F_{8,18}=72.65, P<0.0001$; Fig. 3A). Multiple comparison testing showed significant (SNK, $P<0.05$ ) depth differences for aerial chlorophyll concentrations with 3-30 m not significantly different from one another and significantly different than all other deeper depths (Fig. 3A). Chlorophyll/cell shows a similar pattern (Fig. $3 \mathrm{~A})$, while the chlorophyll $a: c_{2}$ ratio also showed a similar pattern but with finer scale differences between depths (Fig. 3A), which reflect the interplay between chl $a$ and chl $c_{2}$ as photoacclimatization occurs with increasing depth. The aerial cell concentration (cells/ $\mathrm{cm}^{2}$ ) of zooxanthellae within $M$. cavernosa showed a slight increase over the depth range, from $2.3 \times 10^{6}$ cells/ $\mathrm{cm}^{2}$ to $4.2 \times 10^{6}$ cells $/ \mathrm{cm}^{2}$, but it was not significant (ANOVA, $F_{8,18}=2.41, P>0.05$ ). In these same corals, we observed a significant increase in the maximum quantum yield of PSII fluorescence (ANOVA, $F_{8,18}=$ 8.2, $P=0.0006$; Fig. 3B). Multiple comparison testing showed a significant $(\mathrm{SNK}, P<0.05)$ pattern in the relationship between depth and the quantum yield of PSII fluorescence, with the 3- and 9-m samples significantly different from each other and lower than all other depths. Quantum yields were not significantly different between 18 and $76 \mathrm{~m}$, and another break occurred at $91 \mathrm{~m}$ (Fig. 3B).

Reflectance spectra were measured on $M$. cavernosa from all depths and showed decreased reflectances between $\sim 400$ and $500 \mathrm{~nm}$, consistent with absorbance of those wavelengths by chlorophyll. There was also higher reflectance at 550-650 nm with an additional chlorophyll absorption feature centered around $675 \mathrm{~nm}$, and very rapidly increasing reflectance at wavelengths 

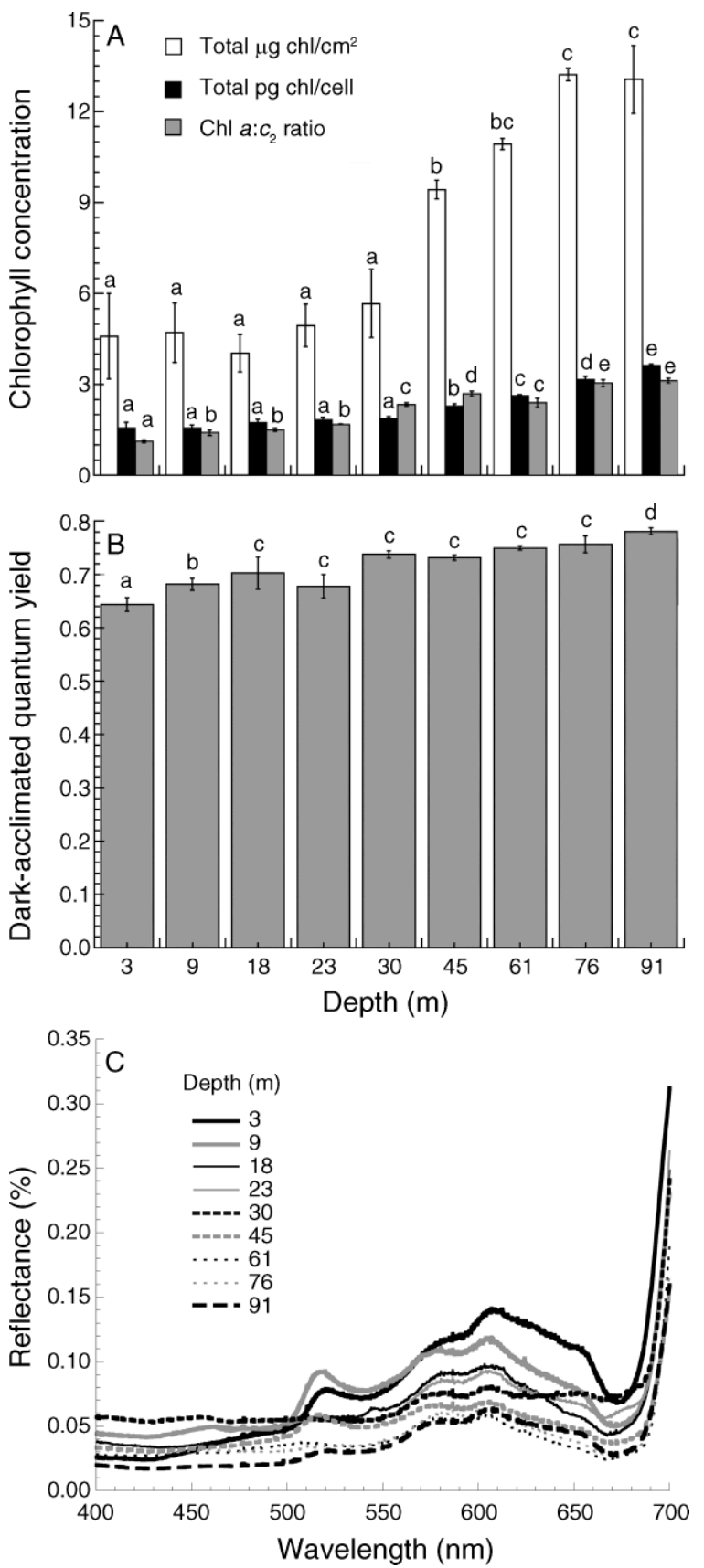

FIG. 3. (A) Total chlorophyll ( $\mathrm{chl} a+c_{2}$ ) normalized to surface area or per zooxanthella and the chl $a: c_{2}$ ratio for colonies (all values mean $\pm \mathrm{SE}$ ) of Montastraea cavernosa collected from 3 to $91 \mathrm{~m}$ depth. (B) Maximum (darkacclimated) quantum yields of PSII fluorescence (mean \pm SE) for colonies of $M$. cavernosa collected from 3 to $91 \mathrm{~m}$ depth. (C) Reflectance spectra (mean percentage) for colonies of $M$. cavernosa collected from 3 to $91 \mathrm{~m}$ depth. Different lowercase letters indicate those depths significantly different from one another using post hoc SNK tests $(P<0.05)$.
$>680 \mathrm{~nm}$ (Fig. 3C). Some individual colonies also exhibited apparent fluorescence features at wavelengths in the range of $510-520 \mathrm{~nm}$ as previously described (Mazel et al. 2003). Overall mean reflectance decreased from $>8 \%$ to $<4 \%$ with increasing depth, which translated into mean absorbances from $92 \%$ to over $96 \%$ in corals. However, the differences in absorbance was not statistically different (ANOVA, $F_{8,18}=1.14, P$ $>0.05)$.

In addition, rapid light curve (RLC) measurements were performed upon all coral samples and the data were fit using nonlinear regression techniques to estimate maximum electron transport rate $\left(\mathrm{ETR}_{\max }\right.$; $\mu \mathrm{mol}$ electrons $\cdot \mathrm{m}^{-2} \cdot \mathrm{s}^{-1}$; Table 1$)$. Statistical analyses of the resulting data showed a significant decrease in ETR $_{\text {max }}$ with increasing depth (ANOVA, $F_{8,18}=3.56, P$ $=0.012$ ). Post hoc multiple comparison testing showed significant groupings of coral $\mathrm{ETR}_{\max }$ according to depth. Corals at $3 \mathrm{~m}$ grouped alone, corals from 9, 18, 23 , and $30 \mathrm{~m}$ grouped together, corals from $45 \mathrm{~m}$ grouped alone, and corals from 61, 76, and $91 \mathrm{~m}$ grouped together (SNK < 0.05). Estimates of GPP (mol $\left.\mathrm{O}_{2} \cdot \mathrm{m}^{-2} \cdot \mathrm{d}^{-1}\right)$ were made on corals from each depth (Table 1). GPP also decreased significantly with depth (ANOVA, $F_{8,18}=856.49, P<0.0001$ ), with significant differences between each (SNK $<0.05$; Table 1$)$. When $\mathrm{ETR}_{\max }$ and GPP were regressed, the functional relationship $\left(y=8.039+0.574 x, R^{2}=0.91\right)$ between the two variables was significant (ANOVA, $F_{1,7}=13.31$, $P=0.008)$.

An analysis of the stable isotope data showed that both the coral tissue fraction (ANOVA, $F_{6,28}=5.17, P=$ 0.001 ; Fig. 4A) and the zooxanthellae fraction (ANOVA, $F_{6,27}=5.85, P=0.0005$; Fig. 4A) became more depleted in $\delta^{13} \mathrm{C}$ values with increased depth. For $\delta^{15} \mathrm{~N}$ there was no significant effect of depth for the coral fraction (ANOVA, $F_{6,28}=1.48, P>0.05$; Fig. 4B) or the zooxanthellae fraction (ANOVA, $F_{6,28}=0.78, P>0.05$; Fig. 4B). Significant depth effects in the $\delta^{13} \mathrm{C}$ signal of the coral skeleton (ANOVA, $F_{7,30}=3.36, P=0.009$; Fig. 4C) were observed, while the $\delta^{18} \mathrm{O}$ values of the skeleton exhibited no effect of depth (ANOVA, $F_{7,30}=2.14, P=$ 0.07). Using the skeletal $\delta^{13} \mathrm{C}$ and $\delta^{18} \mathrm{O}$ values for the calculations of photosynthesis to respiration $(\mathrm{P} / \mathrm{R})$ ratios, a significant decrease with increasing depth (ANOVA, $F_{7,30}=7.54, P<0.0001 ;$ Table 1) was observed with $\mathrm{P} / \mathrm{R}$ ratios at 61 and $91 \mathrm{~m}$ significantly lower than all other depths (SNK, $P<0.05)$.

A total of 16 Symbiodinium ITS2 sequences were recovered from the colonies of $M$. cavernosa, and all were from clade $\mathrm{C}$. These included $\mathrm{C} 1, \mathrm{C} 3, \mathrm{C} 3 \mathrm{~b}, \mathrm{C} 3 \mathrm{e}$, C21.C3d, eight novel sequences designated Mcav1-8, and three unnamed sequences previously published (DQ838544, Garren et al. 2006; AB190269 and AB190265, Reimer et al. 2006) referred to here as Mcav9, Mcav10, and Mcav11, respectively. The Symbiodinium ITS2 sequences recovered from each coral colony is presented, and $\mathrm{C} 3$ was the most common 
sequence throughout the depth range, contributing 35\% of the overall sequence diversity (Fig. 5). In shallowwater colonies $(0-46 \mathrm{~m}), \mathrm{C} 3$ was the dominant sequence (39\%), while in deep-water colonies $(>60 \mathrm{~m})$, the novel sequence Mcav5, not present in shallow-water colonies, was dominant (34\%; Fig. 6). Overall, 12 Symbiodinium ITS2 sequences were recovered from shallow-water corals, and seven from corals at mesophotic depths. Ordination using two-dimensional nonmetric multidimensional scaling (MDS) clearly shows a distinct grouping of the deep-water corals compared to the shallow-water corals based on their Symbiodinum ITS2 sequence composition (Fig. 7). There was a significant difference in the Symbiodinium ITS2 signature from deep-water corals and shallow-water corals (ANOSIM global test, $R=0.491, P>0.05)$, with Mcav5 contributing the highest level of dissimilarity $(21.65 \%)$ between corals from the two groupings.

\section{Discussion}

The light environment is the most important component of the productivity, physiology, and ecology of corals (Falkowski et al. 1990), and restricts the distribution of most species of coral to depths of $60 \mathrm{~m}$ or less. Many species of scleractinian corals cannot photoacclimatize to depths greater than $60 \mathrm{~m}$, although there are exceptions: the coral Leptoseris fragilis from the Red Sea has been found photosynthesizing as deep as $145 \mathrm{~m}$ (Schlichter et al. 1986). The ability of any species of coral to photoacclimatize to the low irradiances of the mesophotic zone is a function of the organization of the photosynthetic apparatus of their symbiotic zooxanthellae, which may in turn have a significant genetic component (Wyman et al. 1987, Lesser et al. 2000, Mass et al. 2007, Frade et al. 2008a). Differences in the ability to photosynthesize will affect the reliance of corals on other trophic strategies, such as heterotrophy, to meet their overall metabolic costs for growth and ultimately their distribution and abundance (Falkowski et al. 1990).

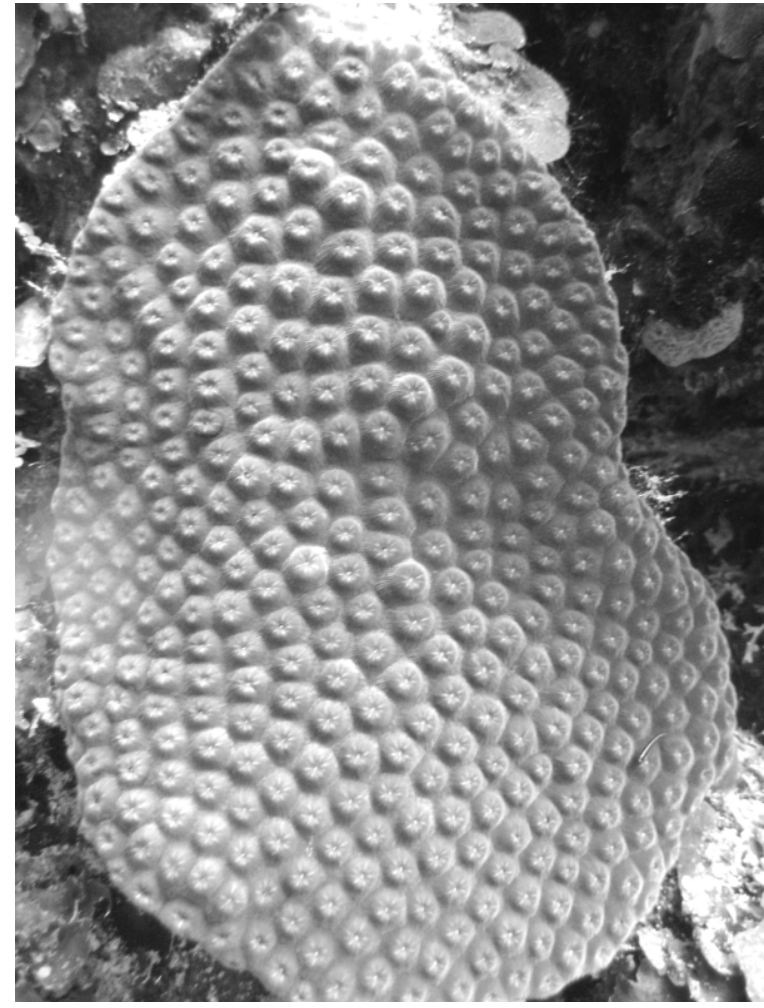

Plate 1. Montastraea cavernosa (flattened morphology) on the mesophotic coral reefs of Lee Stocking Island, Bahamas (76 m depth). Photo credit: M. P. Lesser.

In the optically clear waters of the tropics, the attenuation of solar radiation with increasing depth is a function of the optical properties of the water itself, since there is very little dissolved or particulate matter to absorb the light (Kirk 1994). The mean downwelling irradiance of PAR $\left(K_{\mathrm{dPAR}}\right)$ for the water column on Bock Wall, Lee Stocking Island, Bahamas was 0.057 $\mathrm{m}^{-1}\left( \pm 0.006 \mathrm{~m}^{-1} \mathrm{SE}\right)$ with the midpoint of the euphotic zone at $40 \mathrm{~m}$ and the compensation depth at $81 \mathrm{~m}$. In the

TABLE 1. Summary of measured and calculated optical parameters (some \pm SE) for the coral Montastraea cavernosa from Lee Stocking Island, Bahamas.

\begin{tabular}{ccccccc}
\hline \hline $\begin{array}{c}\text { Depth } \\
(\mathrm{m})\end{array}$ & $E_{\mathrm{d}}$ & $A$ & ETR $_{\max }$ & $\Phi_{\mathrm{m}}$ & GPP & P/R ratio \\
\hline 3 & 960 & $0.917 \pm 0.028$ & $26.98 \pm 1.22$ & 0.3134 & $2.38 \pm 0.073$ & $3.19^{\mathrm{a}} \pm 0.17$ \\
9 & 651 & $0.924 \pm 0.018$ & $21.82 \pm 1.56$ & 0.5170 & $2.67 \pm 0.051$ & $2.54^{\mathrm{a}} \pm 0.31$ \\
15 & 354 & $0.938 \pm 0.017$ & $21.05 \pm 2.34$ & 0.0645 & $1.85 \pm 0.033$ & $2.18^{\mathrm{b}} \pm 0.19$ \\
23 & 223 & $0.935 \pm 0.015$ & $17.09 \pm 0.71$ & 0.0691 & $1.24 \pm 0.021$ & $1.96^{\mathrm{b}} \pm 0.24$ \\
30 & 183 & $0.932 \pm 0.013$ & $15.96 \pm 1.17$ & 0.0740 & $1.09 \pm 0.015$ & $2.40^{\mathrm{b}} \pm 0.16$ \\
45 & 92 & $0.951 \pm 0.010$ & $13.34 \pm 0.68$ & 0.0815 & $0.62 \pm 0.006$ & $2.04^{\mathrm{b}} \pm 0.31$ \\
61 & 48 & $0.960 \pm 0.011$ & $10.47 \pm 0.69$ & 0.0872 & $0.35 \pm 0.004$ & $1.13^{\mathrm{c}} \pm 0.36$ \\
76 & 24 & $0.959 \pm 0.010$ & $8.86 \pm 0.85$ & 0.0912 & $0.18 \pm 0.002$ & $\mathrm{ND}$ \\
91 & 13 & $0.963 \pm 0.012$ & $6.55 \pm 1.48$ & 0.0946 & $0.10 \pm 0.001$ & $0.98^{\mathrm{c}} \pm 0.89$
\end{tabular}

Notes: Abbreviations are $E_{\mathrm{d}}$, downwelling irradiance $\left(\mu \mathrm{mol}\right.$ quanta $\left.\cdot \mathrm{m}^{-2} \cdot \mathrm{s}{ }^{-1}\right) ; A$, absorbance (absorbance units); $\mathrm{ETR}_{\max }$, maximum electron transport rate (electrons $\cdot \mathrm{m}^{-2} \cdot \mathrm{s}^{-1}$ ); $\Phi_{\mathrm{m}}$, maximum quantum yield of photosynthesis ( $\mathrm{mol} \mathrm{O}_{2}$ evolved per mol quanta absorbed); GPP, gross primary productivity $\left(\mathrm{mol} \mathrm{O}_{2} \cdot \mathrm{m}^{-2} \cdot \mathrm{d}^{-1}\right) ; \mathrm{P} / \mathrm{R}$ ratio, ratio of photosynthesis to respiration calculated using the skeletal stable isotope data; ND, no data. Shared superscripts indicate groups not significantly different from each other (Student-Newman-Keuls [SNK] multiple comparison test, $P<0.05$ ). 

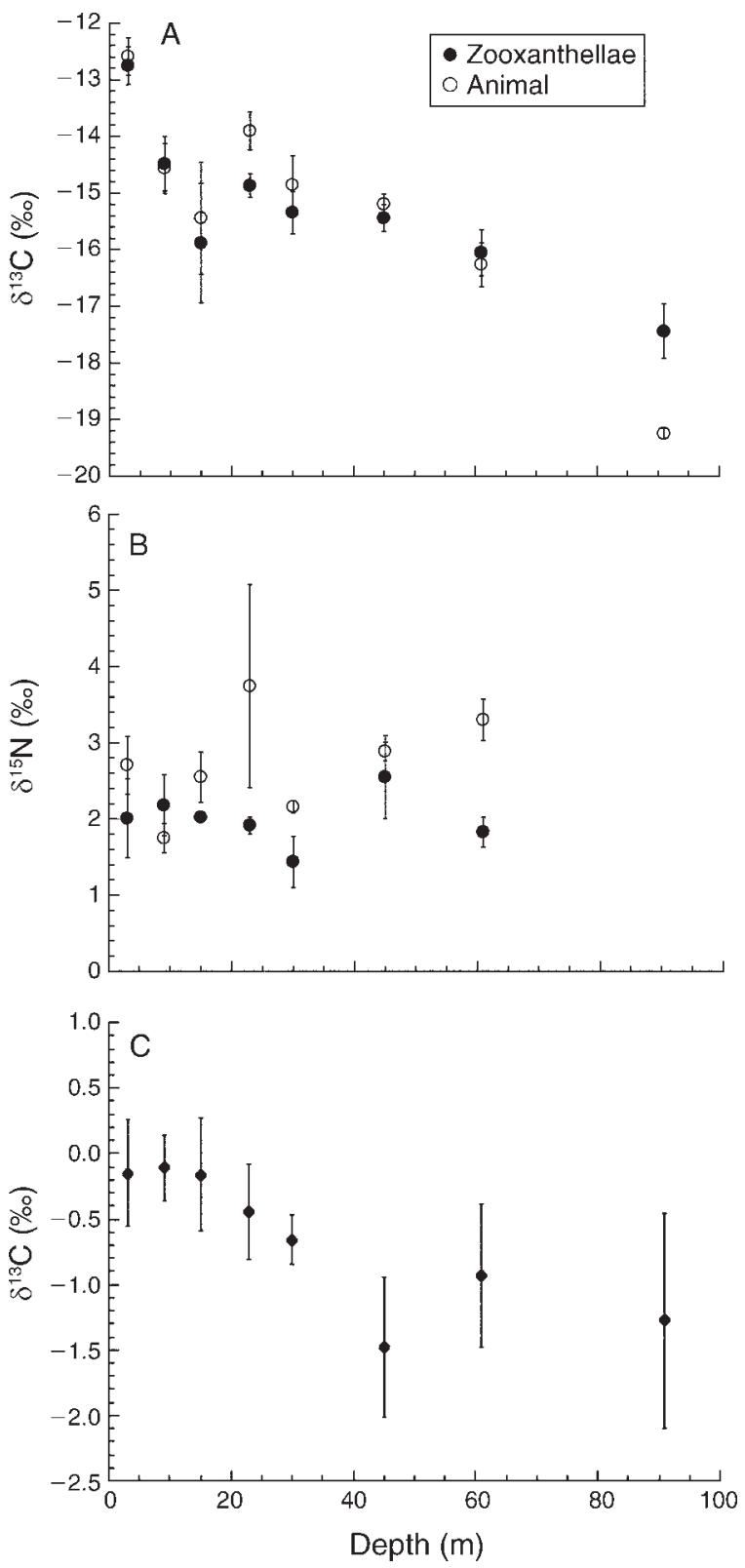

FIG. 4. (A) Stable $\delta^{13} \mathrm{C}$ isotope results (mean $\pm \mathrm{SE}$ ) for the animal and zooxanthellae compartments for colonies of Montastraea cavernosa collected from 3 to $91 \mathrm{~m}$ depth. (B) Stable $\delta^{15} \mathrm{~N}$ isotope results (mean $\pm \mathrm{SE}$ ) for the animal and zooxanthellae compartments for colonies of $M$. cavernosa collected from 3 to $91 \mathrm{~m}$ depth. (C) Stable $\delta^{13} \mathrm{C}$ isotope results (mean $\pm \mathrm{SE}$ ) for the skeleton from colonies of $M$. cavernosa collected from 3 to $91 \mathrm{~m}$ depth. All discrete measurements are from Bock Wall, Lee Stocking Island, Bahamas.

Caribbean, Montastraea cavernosa can occur at depths exceeding $90 \mathrm{~m}$ in the mesophotic zone (Reed 1985). At these depths $M$. cavernosa and many other species of coral grow in large flat plates to maximize light capture that is typical of a phenotypically plastic, morphological response to decreasing irradiances (Todd 1998). The corals spanning our depth gradient also exhibited morphological phenotypic plasticity, with a significant increase in the plating morphology with increased depth, albeit in fewer individuals. Additionally, significant changes in the abundance of photosynthetic pigments with depth increases the absorption of as much light as possible, but self shading then occurs (Lesser et al. 2000), and corals essentially become "black boxes" in an effort to absorb all of the available photons. Still, light at these depths appears to limit photosynthesis (Falkowski et al. 1990). One feature of coral photobiology that may counteract these negative attributes of photoaclimatization to low irradiances is that corals display a unique mechanism to enhance the residence time of photons through multiple scattering by the skeleton (Enriquéz et al. 2005). This phenomenon can enhance the absorption of light several fold and potentially counteract the effects of self shading in mesophotic corals (Enriquéz et al. 2005) and maintain corals at, or above, irradiances associated with the compensation depth despite actually residing at deeper depths. For $M$. cavernosa, decreasing rates of photosynthetic electron transport and lower quantum yields of photosynthesis translate into lower rates of gross primary productivity (Table 1). Additionally, the $\mathrm{P} / \mathrm{R}$ ratio of corals decreases with depth (Table 1), and for corals at $91 \mathrm{~m}$, it is less than unity, indicating a decreasing dependence on autotrophy. Temperature differences between depths could also affect rates of productivity, but changes in temperature with depth are relatively insignificant $\left(\sim 4^{\circ} \mathrm{C}\right.$ over the $90 \mathrm{~m}$ measured). Additionally, the $\delta^{18} \mathrm{O}$ isotopic signature of the coral skeletons, a reliable indicator of changes in seawater temperature (Dunbar and Wellington 1981), was not significantly different with depth, but these results could also be because decreases in temperature can be hidden by decreases in calcification.

The isotopic signature of $\delta^{13} \mathrm{C}$ for both zooplankton and particulate organic material ranges from $-14 \%$ to $-25 \%$ and for $\delta^{15} \mathrm{~N}$ it was $4-6 \%$ (Land et al. 1975, Owens 1987, Peterson and Fry 1987) and mean values of $-19.9 \%$ for $\delta^{13} \mathrm{C}$ and $-3.6 \%$ for $\delta^{15} \mathrm{~N}$ POM from waters adjacent to the Florida Keys (Lamb and Swart 2008). For $\delta^{13} \mathrm{C}$ very little metabolic enrichment occurs while enrichment in nitrogen per trophic level averages 2.6\%o (Owens 1987, Peterson and Fry 1987). For M. cavernosa coral tissue, zooxanthellae, and skeleton, the $\delta^{13} \mathrm{C}$ is progressively more depleted with depth. The slight enrichment observed in the coral vs. zooxanthellae $\delta^{13} \mathrm{C}$ signatures is probably due to the translocation of fixed carbon to the host (Muscatine et al. 1989). The difference in the host $\delta^{13} \mathrm{C}$ isotopic signature at $91 \mathrm{~m}$ compared to its zooxanthellae is consistent with decreased translocation and an increased dependence on heterotrophy vs. translocated photosynthate. The depleted $\delta^{13} \mathrm{C}$ values of the zooxanthellae with increasing depth are also consistent with an increase in isotopic discrimination due to a decrease in photosynthesis and an increase in the proportion of metabolically fixed 


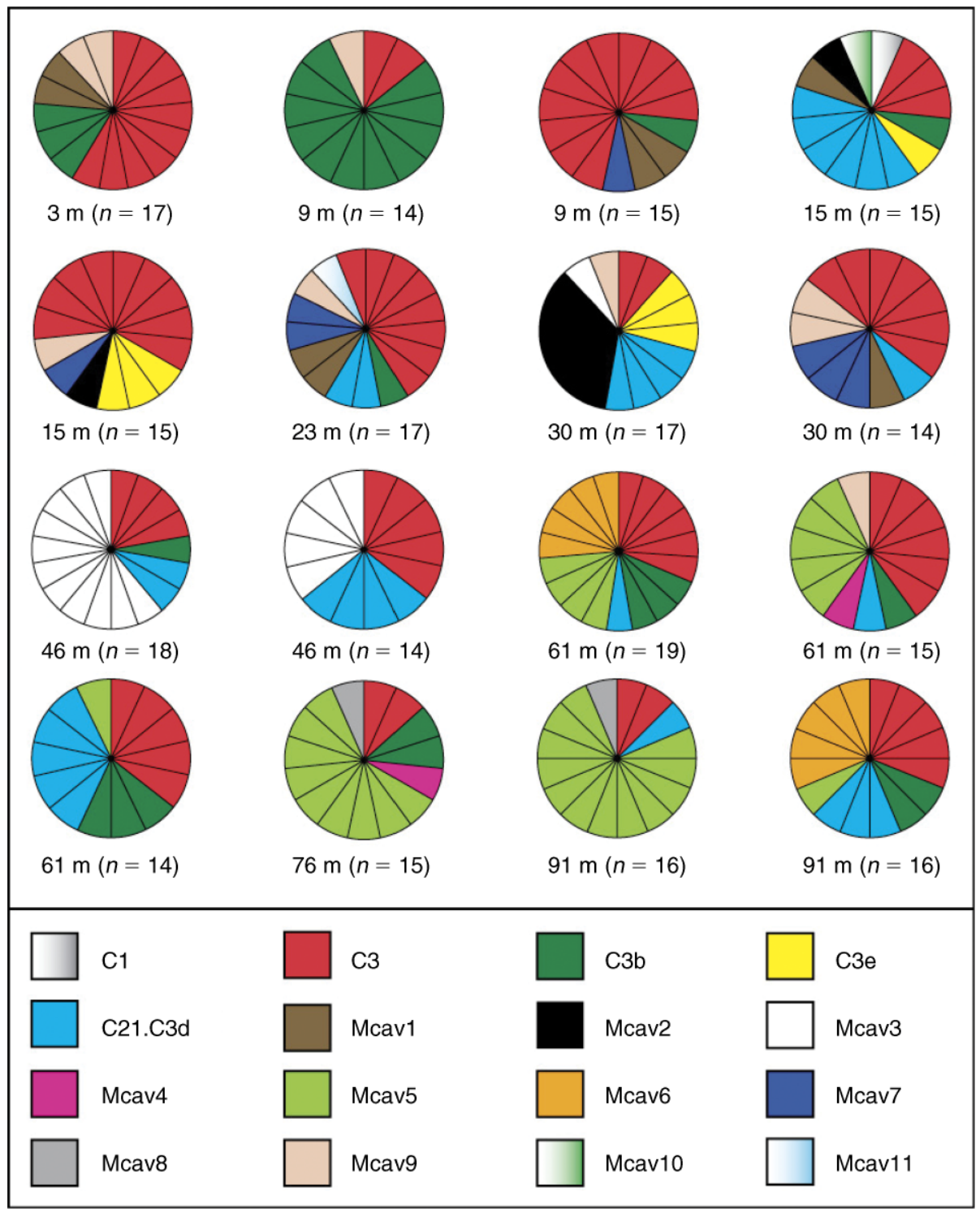

FIG. 5. Diversity of rDNA ITS2 symbiont types isolated from colonies of Montastraea cavernosa from 3 to $91 \mathrm{~m}$ depth. Each pie chart represents one coral colony, and sectors correspond to individual ITS2 sequence types. The size of the sector indicates within-colony abundance relative to the total number of clones examined, which is given below each chart $(n)$. A color key of known and novel ITS2 symbiont types is provided below the pie charts.

carbon dioxide (Muscatine et al. 1989), but back translocation of organic carbon from the host to zooxanthellae cannot be ruled out either (Muscatine et al. 1989). Skeletal $\delta^{13} \mathrm{C}$ values also show a significant depletion with increasing depth. Changes in skeletal $\delta^{13} \mathrm{C}$ values reflect long-term integrated changes in coral metabolism, specifically photosynthesis and respiration, which are affected by the availability of light and heterotrophic food sources such as zooplankton (Grottoli and Wellington 1999, Grottoli 2002). The $\delta^{13} \mathrm{C}$ of dissolved inorganic carbon and particulate organic material is $\sim 0 \%$ and $-14 \%$ o to $-25 \%$, respectively (Peterson and Fry 1987). As photosynthesis increases, the $\delta^{13} \mathrm{C}$ values of the skeleton increases, while heterotrophy caused a decrease in skeletal $\delta^{13} \mathrm{C}$ values. In this study, the decrease in $\delta^{13} \mathrm{C}$ values for $M$. cavernosa between 23 and $45 \mathrm{~m}$ is consistent with an increase in heterotrophic feeding, while the increase at $61 \mathrm{~m}$ indicates that metabolic fractionation is no longer driving the isotopic signal and that equilibrium kinetics are operating. Feeding at depth would likely be dominated by zooplankton whose $\delta^{13} \mathrm{C}$ values on coral reefs have been reported to be between $-17.1 \%$ and $-19.8 \%$ (Land et al. 1975). This is consistent with the observed change in skeletal $\delta^{13} \mathrm{C}$ signatures with depth for $M$. cavernosa (data from this study), Porites 


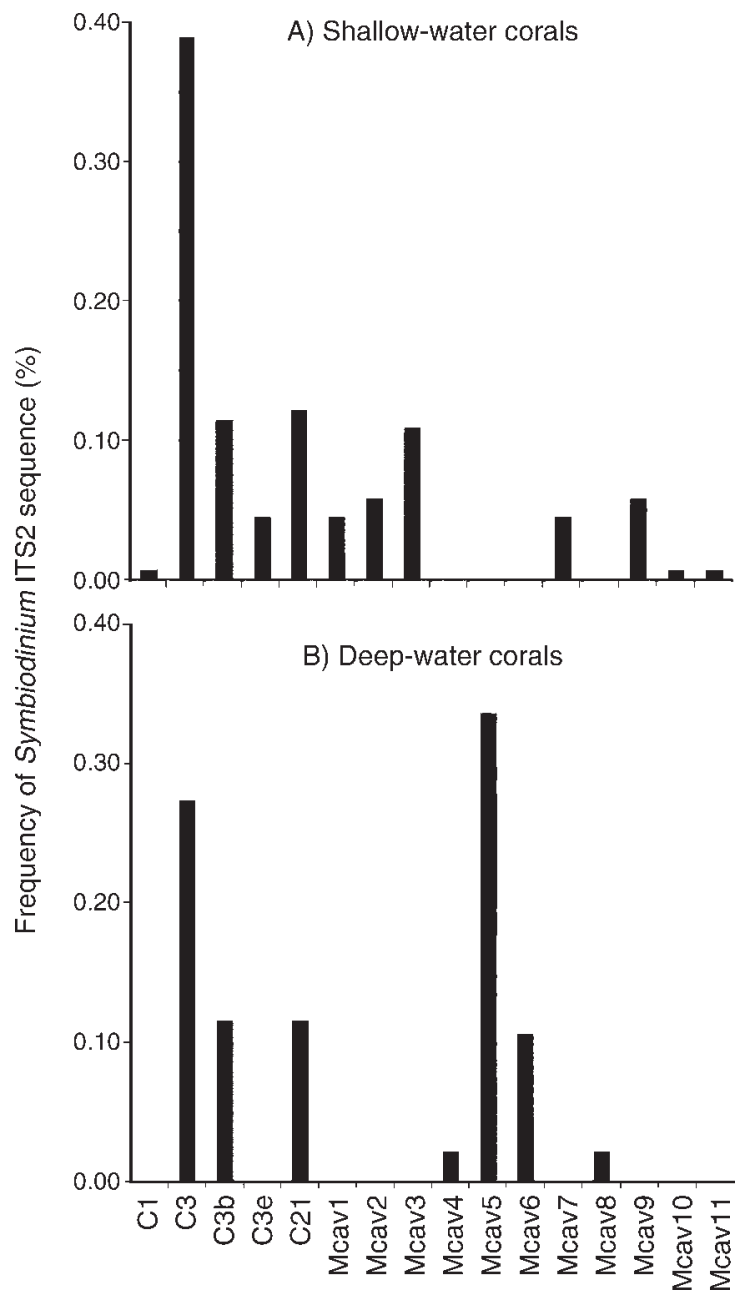

FIG. 6. Percentage frequency of Symbiodinium ITS2 sequences from colonies of Montastraea cavernosa sampled from (A) shallow-water colonies (0-46 m depth) and (B) mesophotic (deep) colonies (61-91 $\mathrm{m}$ depth).

compressa (Grottoli 1999), Pavona clavus, and Pavona gigantea (Grottoli and Wellington 1999).

The $\delta^{15} \mathrm{~N}$ values for the coral compartment ranged from $1.75 \%$ to $3.74 \%$, while the zooxanthellae $\delta^{15} \mathrm{~N}$ values ranged from $1.44 \%$ to $2.55 \%$; that is consistent with previous observations for $M$. cavernosa (Muscatine and Kaplan 1994). Despite the fact that coral $\delta^{15} \mathrm{~N}$ signatures were generally higher than the zooxanthellae, there were no differences in the $\delta^{15} \mathrm{~N}$ composition of the host tissue or zooxanthellae with increasing depth. The enriched nitrogen isotopic signal of the coral tissues when compared to its zooxanthellae was more consistent with the recycling of internal ammonia and amino acids between the host and zooxanthellae, and with the metabolic fractionation associated with changes in trophic level (Muscatine and Kaplan 1994, Swart et al. 2005). Alternatively, other sources of dissolved inorganic nitrogen, such as nitrate, could be readily available to mesophotic corals from upwelling or internal waves.
With a $\delta^{15} \mathrm{~N}$ signature for nitrate of $4-6 \%$ (Lamb and Swart 2008) similar $\delta^{15} \mathrm{~N}$ signals in the zooxanthellae and animal compartments would be observed.

There is a clear partitioning of the Symbiodinium community harbored by shallow-water corals $(0-46 \mathrm{~m})$ and deep-water corals $(>60 \mathrm{~m})$. The novel Symbiodinium sequence recovered from deep-water corals, Mcav5, and others (Mcav4, Mcav6, Mcav8) likely represent deepwater specialists. The change in the zooxanthellae assemblages occurs at the transitional depths where light becomes increasingly limited for photosynthesis, and heterotrophy takes on an increased role in the nutrition of $M$. cavernosa. A similar pattern of Symbiodinium sp. distribution was recently reported for the Caribbean coral Madracis spp. These species were distributed along a depth gradient from 5 to $40 \mathrm{~m}$ that showed strong correlations with host-specific zooxanthellae haplotypes (Frade et al. 2008b). The strongest case for explaining the vertical distribution of corals as a result of zooxanthellae haplotype comes from the work of Iglesias-Prieto et al. (2004). A combination of physiological and genetic differences were coupled to reciprocal transplant studies across a depth gradient to show that the deep coral Pavona gigantean experienced pronounced photoinhibition that could be seen eight months post-transplantation. This was in contrast to the coral Pocillopora verrucosa, which after being transplanted to deeper depths never showed any evidence that photosynthesis was saturated, and was likely in a state of net negative energy acquisition (Iglesias-Prieto et al. 2004).

These studies illustrate the important influence of the zooxanthellae genotype on the photosynthetic performance of a coral. However, for corals at mesophotic depths we do not yet know whether there is net positive photosynthesis produced by the large populations of zooxanthellae found in corals at these depths. Despite

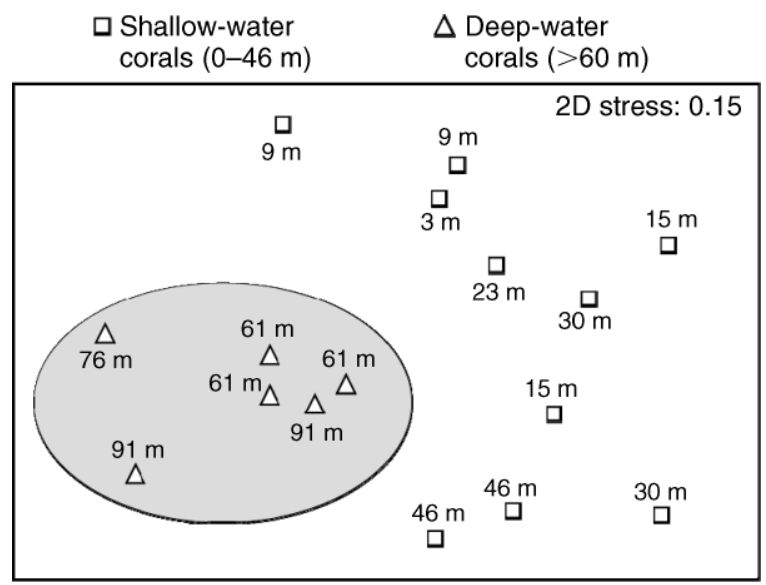

FIG. 7. Two-dimensional, nonmetric multidimensional scaling ordination of the Symbiodinium sequence composition in colonies of Montastraea cavernosa of different depths. The gray area represents the grouping of mesophotic colonies. 
significantly elevated concentrations of photosynthetic pigment and the increase in absorbance of $M$. cavernosa with increasing depth, the maximum electron transport rate and calculated quantum yields of photosynthesis decrease significantly, leading to decreases in calculated gross primary productivity and photosynthesis/respiration $(\mathrm{P} / \mathrm{R})$ ratios. This decrease in productivity will ultimately lead to decreases in translocated photosynthate from the zooxanthellae to host tissues and to an increased dependency on heterotrophic food sources for corals at mesophotic depths. Additional evidence for a transition from autotrophy to heterotrophy is clearly seen in the $\delta^{13} \mathrm{C}$ signatures in the animal tissue and skeleton. Where do these heterotrophic resources come from? $M$. cavernosa is a consumer of zooplankton (Sebens et al. 1998) that undergoes diel vertical migrations from deep depths $(>150 \mathrm{~m})$ to mesophotic depths. Alternatively, zooplankton could be delivered by upwelling or internal wave events that carry nutrientrich (e.g., nitrate) cold water with high concentrations of zooplankton. This has been described on a number of Caribbean reefs including Lee Stocking Island, Bahamas (Leichter et al. 2006). Internal waves are an important mechanism of bottom-up forcing and can affect the composition and dynamics of benthic communities (Gili and Coma 1998), as well as the growth of corals at mesophotic depths (Leichter and Genovese 2006). While internal waves have been demonstrated to occur around Lee Stocking Island, the $\delta^{18} \mathrm{O}$ signatures of the skeletons of $M$. cavernosa during this study do not show any signal consistent with internal waves and the intrusion of deep cold water to mesophotic depths.

While the diversity of zooxanthellae changes with increasing depth, we do not know what changes in the population genetics of the host coral might confer specific advantages at mesophotic depths. We know from studies using nuclear and mitochondrial markers that there does not appear to be any depth or location differences for M. cavernosa (Billinghurst et al. 1997, Snell et al. 1998), but more robust techniques such as amplified fragment length polymorphisms (Fukami et al. 2004, Brazeau et al. 2005) for samples from both the Bahamas and the Cayman Islands along deep vertical gradients suggest both geographic and depth-dependent population differences that may yet prove to be important (M. P. Lesser, M. Slattery, and D. Brazeau, unpublished manuscript).

Mesophotic corals and coral reefs are vastly understudied. The potential of these communities to provide essential habitat that can be used as refugia and source populations of larvae for fish and corals may be important in an era of continuing global climate change. Studies on the biophysical coupling of shallow and mesophotic reefs is becoming essential for understanding the ecology of reef systems in general, and specifically whether we should put in place special measures to protect these unique habitats. The observations presented here point out the unique multidisci- plinary approach required to understand these important ecosystems, and in particular the depthdependent variability in the physiological ecology of shallow and mesophotic populations of $M$. cavernosa.

\section{ACKNOWLEDGMENTS}

This work was supported by grants from NOAA's Ocean Exploration Program and NOAA's National Undersea Research Program. We thank the Bigelow Laboratory for Ocean Science Flow Cytometry facility for the analysis of water column phytoplankton. The experiments conducted for this study comply with the current laws of the Bahamas and the United States of America.

\section{Literature Cited}

Amaral, F. D. 1994. Morphological variation in the reef coral Montastraea cavernosa in Brazil. Coral Reefs 13:113-117.

Bak, R. P. M., G. Nieuwland, and E. H. Meesters. 2005. Coral reef crisis in deep and shallow reefs: 30 years of constancy and change in reefs of Curacao and Bonaire. Coral Reefs 24: 475-479.

Billinghurst, Z., A. E. Douglas, and H. G. Trapido-Rosenthal. 1997. On the genetic diversity of the symbiosis between the coral Montastraea cavernosa and zooxanthellae in Bermuda. Proceedings of the Eighth International Coral Reef Symposium 2:1291-1294.

Bray, J. R., and J. T. Curtis. 1957. An ordination of the upland forest communities of southern Wisconsin. Ecological Monographs 27:325-349.

Brazeau, D., P. W. Sammarco, and D. F. Gleason. 2005. A multi-locus genetic assignment technique to assess local recruitment of Agaricia agaricites on coral reefs. Marine Biology 147:1141-1148.

Clarke, K. R., and R. M. Warwick. 2001. Change in marine communities: an approach to statistical analysis and interpretation. Second edition. PRIMER-E, Plymouth, UK.

Davies, P. S. 1980. Respiration in some Atlantic reef corals in relation to vertical distribution and growth form. Biological Bulletin 158:187-194.

Dunbar, R. B., and G. M. Wellington. 1981. Stable isotopes in a branching coral monitor seasonal temperature variation. Nature 293:453-455.

Dustan, P. 1982. Depth-dependent photoadaptation by zooxanthellae of the reef coral Montastea annularis. Marine Biology 68:253-264.

Enriquéz, S., E. R. Méndez, and R. Iglesias-Prieto. 2005. Multiple scattering on coral skeletons enhances light absorption by symbiotic algae. Limnology and Oceanography 50:1025-1032.

Falkowski, P. G., P. L. Jokiel, and R. A. Kinzie III. 1990. Irradiance and corals. Pages 89-107 in Z. Dubinsky, editor. Coral reefs. Elsevier, Amsterdam, The Netherlands.

Fitt, W. K., and M. E. Warner. 1995. Bleaching patterns of four species of Caribbean reef corals. Biological Bulletin 189: 298-307.

Frade, P. R., P. Bongaerts, A. J. S. Winkelhagen, L. Tok, and R. P. M. Bak. 2008a. In situ photobiology of corals over large depth ranges: a multivariant analysis on the roles of environment, host, and algal symbiont. Limnology and Oceanography 53:2711-2723.

Frade, P. R., F. de Jongh, F. Vermeulen, J. van Bleijswijk, and R. P. M. Bak. 2008b. Variation in symbiont distribution between closely related coral species over large depth ranges. Molecular Ecology 17:691-703.

Fricke, H., and B. Knauer. 1986. Diversity and spatial pattern of coral communities in the Red Sea upper twilight zone. Oecologia 71:29-37.

Fricke, H., and D. Meischner. 1985. Depth limits of Bermudian scleractinian corals: a submersible survey. Marine Biology 88:175-187. 
Fukami, H., A. F. Budd, G. Paulay, A. Solé-Cava, C. A. Chen, and N. Knowlton. 2004. Conventional taxonomy obscures deep divergence between Pacific and Atlantic corals. Nature 427:832-835.

Gardner, T. A., I. M. Cote, J. A. Gill, A. Grant, and A. R. Watkinson. 2003. Long-term region-wide declines in Caribbean corals. Science 301:958-960.

Garren, M., S. M. Walsh, A. Caccone, and N. Knowlton. 2006. Patterns of association between Symbiodinium and members of the Montastraea annularis species complex on spatial scales ranging from within colonies to between geographic regions. Coral Reefs 25:503-512.

Gattuso, J.-P., B. Gentilli, C. M. Duarte, J. A. Kleypas, J. J. Middelburg, and D. Antoine. 2006. Light availability in the coastal ocean: impact on the distribution of benthic photosynthetic organisms and heir contribution to primary production. Biogeoscience 3:489-513.

Gili, J.-F., and R. Coma. 1998. Benthic suspension feeders: their paramount role in littoral marine food webs. Trends in Ecology and Evolution 13:316-321.

Goreau, T. F., and J. W. Wells. 1967. The shallow-water scleractinia of Jamaica: revised list of species and their vertical distribution range. Bulletin of Marine Science 17: $442-453$.

Grigg, R. W. 2006. Depth limit for reef building corals in the Au'au Channel, S. E. Hawaii. Coral Reefs 25:77-84.

Grottoli, A. G. 1999. Variability of stable isotopes and maximum linear extension in coral skeletons at Kaneohe Bay, Hawaii. Marine Biology 135:437-449.

Grottoli, A. G. 2002. Effect of light and brine shrimp levels on skeletal $\delta^{13} \mathrm{C}$ values in the Hawaiian coral Porites compressa: a tank experiment. Geochemica et Cosmochimica Acta 66: 1955-1967.

Grottoli, A. G., and G. M. Wellington. 1999. Effect of light and zooplankton on skeletal $\delta^{13} \mathrm{C}$ values in the eastern Pacific corals Pavona clavus and Pavona gigantea. Coral Reefs 18: 29-41.

Heikoop, J. M., J. J. Dunn, M. J. Risk, H. P. Schwarz, T. A. McConnaughey, and I. M. Sandeman. 2000. Separation of kinetic and metabolic isotope effects in carbon-13 records preserved in reef coral skeletons. Geochemica et Cosmochimica Acta 64:975-987.

Hochberg, E. J., and M. J. Atkinson. 2008. Coral reef benthic productivity based on optical absorptance and light-use efficiency. Coral Reefs 27:49-59.

Hughes, T. P., et al. 2003. Climate change, human impacts, and the resilience of coral reefs. Science 301:929-933.

Hunter, R. L., T. C. LaJeunesse, and S. R. Santos. 2007. Structure and evolution of the rDNA internal transcribed spacer (ITS) region 2 in the symbiotic dinoflagellates (Symbiodinium, Dinophyta). Journal of Phycology 43:120 128.

Iglesias-Prieto, R., V. H. Beltrán, T. C. LaJeunesse, H. ReyesBonilla, and P. E. Thomé. 2004. Different algal symbionts explain the vertical zonation of dominant reef corals in the eastern Pacific. Proceedings of the Royal Society of London B 271:1757-1763.

Jackson, J. B. C. 2008. Ecological extinction and evolution in the brave new world. Proceedings of the National Academy of Sciences (USA) 105:11458-11465.

Jarrett, B. D., A. C. Hine, R. B. Halley, D. F. Naar, S. D. Locker, A. C. Neumann, D. Twichell, C. Hu, B. T. Donahue, W. C. Jaap, D. Palandro, and K. Ciembronowicz. 2005. Strange bedfellows - a deep water hermatypic coral reef superimposed on a drowned barrier island; southern Pulley Ridge, SW Florida platform margin. Marine Geology 214: 295-307.

Jeffrey, S. W., and G. F. Humphrey. 1975. New spectrophotometric equations for determining chlorophylls $a, b, c$, and $c_{2}$ in higher plants, algae and natural phytoplankton. Biochemie und Physiologie der Pflanzen 167:191-194.
Kahng, S. E., and C. D. Kelley. 2007. Vertical zonation of megabenthic taxa on a deep photosynthetic reef (50-140 m) in Au'au Channel, Hawaii. Coral Reefs 26:679-687.

Kirk, J. T. O. 1994. Light and photosynthesis in aquatic ecosystems. Cambridge University Press, London, UK.

Kühlmann, D. H. H. 1983. Composition and ecology of deepwater coral association. Helgoländer Meersesun 36:183-204.

LaBarbera, M. 1989. Analyzing body size as a factor in ecology and evolution. Annual Review of Ecology and Systematics 20:97-117.

LaJeunesse, T. C. 2002. Diversity and community structure of symbiotic dinoflagellates from Caribbean coral reefs. Marine Biology 141:387-400.

Lamb, K., and P. K. Swart. 2008. The carbon and nitrogen stable isotopic values of particulate organic material from the Florida Keys: a temporal and spatial study. Coral Reefs 27: 351-362.

Land, L. S., J. C. Lang, and B. C. Smith. 1975. Preliminary observations on the carbon isotopic composition of some reef coral tissues and symbiotic zooxanthellae. Limnology and Oceanography 20:283-287.

Lasker, H. R. 1981. Phenotypic variation in the coral Montastraea cavernosa and its effects on colony energetics. Biological Bulletin 160:292-302.

Lehnert, H., and H. Fischer. 1999. Distribution patterns of sponges and corals down to $107 \mathrm{~m}$ off north Jamaica. Memoirs of the Queensland Museum 44:307-316.

Leichter, J. J., and S. J. Genovese. 2006. Intermittent upwelling and subsidized growth of the scleractinian coral Madarcis mirabilis on the deep fore-reef slope of Discovery Bay, Jamaica. Marine Ecology Progress Series 316:95-103.

Leichter, J. J., B. Helmuth, and A. M. Fisher. 2006. Variation beneath the surface: quantifying complex thermal environments on coral reefs in the Caribbean, Bahamas, and Florida. Journal of Marine Research 64:563-588.

Lesser, M. P. 1996. Exposure of symbiotic dinoflagellates to elevated temperatures and ultraviolet radiation causes oxidative stress and inhibits photosynthesis. Limnology and Oceanography 41:271-283.

Lesser, M. P. 2004. Experimental biology of coral reef ecosystems. Journal of Experimental Marine Biology and Ecology 300:217-252.

Lesser, M. P., and J. H. Farrell. 2004. Exposure to solar radiation increases damage to both host tissues and algal symbionts of corals during thermal stress. Coral Reefs 23: 367-377.

Lesser, M. P., C. Mazel, D. Phinney, and C. S. Yentsch. 2000. Light absorption and utilization by colonies of the congeneric hermatypic corals Montastraea faveolata and Montastraea cavernosa. Limnology and Oceanography 45:76-86.

Lesser, M. P., S. E. Shumway, T. Cucci, and J. Smith. 1992. Impact of fouling organisms on mussel rope culture: interspecific competition for food among suspension-feeding invertebrates. Journal of Experimental Marine Biology and Ecology 165:91-102.

Lesser, M. P., M. Slattery, and J. J. Leichter. 2009. Ecology of mesophotic coral reefs. Journal of Experimental Marine Biology and Ecology 375:1-8.

Liddell, W. D., W. E. Avery, and S. L. Ohlhorst. 1997. Patterns of benthic community structure, 10-250 m, the Bahamas. Proceedings of the Eighth International Coral Reef Symposium 1:437-442.

Mass, T., S. Einbinder, E. Brokovich, N. Shashar, R. Vargo, J. Erez, and Z. Dubinsky. 2007. Photoacclimation of Stylophora pistillata to light extremes: metabolism and calcification. Marine Ecology Progress Series 334:93-102.

Mazel, C. H., M. P. Lesser, M. Y. Gorbunov, T. M. Barry, J. H. Farrell, K. D. Wyman, and P. G. Falkowski. 2003. Green-fluorescent proteins in Caribbean corals. Limnology and Oceanography 48:402-411. 
Menza, C., M. Kendall, and S. Hile. 2008. The deeper we go the less we know. International Journal of Tropical Biology 56: $11-24$.

Moberg, F., and C. Folke. 1999. Ecological goods and services of coral reef ecosystems. Ecological Economics 29:215-233.

Muscatine, L., and I. R. Kaplan. 1994. Resource partitioning by reef corals as determined from stable isotope composition II. $\delta^{15} \mathrm{~N}$ of zooxanthellae and animal tissue versus depth. Pacific Science 48:304-312.

Muscatine, L., J. W. Porter, and I. R. Kaplan. 1989. Resource partitioning by reef corals as determined from stable isotope composition I. $\delta^{13} \mathrm{C}$ of zooxanthellae and animal tissue versus depth. Marine Biology 100:185-193.

Owens, N. J. P. 1987. Natural variations in ${ }^{15} \mathrm{~N}$ in the marine environment. Advances in Marine Biology 24:389-451.

Peterson, B. J., and B. Fry. 1987. Stable isotopes in ecosystem studies. Annual Review of Ecology and Systematics 18:293320.

Platt, T., C. L. Gallegos, and W. G. Harrison. 1980. Photoinhibition of photosynthesis in natural assemblages of marine phytoplankton. Journal of Marine Research 38:687-701.

Reed, J. K. 1985. Deepest distribution of Atlantic hermatypic corals discovered in the Bahamas. Proceedings of the Fifth International Coral Reef Symposium 6:249-254.

Reimer, J. D., K. Takishita, S. Ono, T. Maruyama, and J. Tsukahara. 2006. Latitudinal and intracolony ITS-rDNA sequence variation in the symbiotic dinoflagellate genus Symbiodinium (Dinophyceae) in Zoanthus sansibaricus (Anthozoa: Hexacorallia). Phycological Research 54:122-132.

Riegl, B., and W. E. Piller. 2003. Possible refugia for reefs in times of environmental stress. International Journal of Earth Science 92:520-531.

Rodrigues, L. J., and A. G. Grottoli. 2006. Calcification rate and the stable carbon, oxygen, and nitrogen isotopes in the skeleton, host tissue, and zooxanthellae of bleached and recovering Hawaiian corals. Geochimica et Cosmochimica Acta 70:2781-2789.

Sampayo, E. M., L. Franceschinis, and O. Hoegh-Guldberg. 2007. Niche partitioning of closely related symbiotic dinoflagellates. Molecular Ecology 16:3721-3733.

Schlichter, D., H. W. Fricke, and W. Weber. 1986. Light harvesting by wavelength transformation in a symbiotic coral of the Red Sea twilight zone. Marine Biology 91:403-407.

Schultz, J., T. Müller, M. Achtziger, P. N. Seibel, T. Dandekar, and M. Wolf. 2006. The internal transcribed spacer 2 database - a web server for (not only) low level phylogenetic analyses. Nucleic Acids Research 34:W704-707.

Sebens, K. P., S. P. Grace, B. Helmuth, E. J. Maney, Jr., and J. S. Miles. 1998. Water flow and prey capture by three scleractinian corals, Madracis mirabilis, Montastraea cavernosa and Porites porites in a field enclosure. Marine Biology 131:347-360.

Seibel, P. N., T. Müller, T. Dandekar, J. Schultz, and M. Wolf. 2006. 4SALE - a tool for synchronous RNA sequence and secondary structure alignment and editing. BMC Bioinformatics 7:498.

Seibel, P. N., T. Müller, T. Dandekar, and M. Wolf. 2008. Synchronous visual analysis and editing of RNA sequence and secondary structure alignments using 4SALE. BMC Research Notes 1:91.

Selig, C., M. Wolf, T. Müller, T. Dandekar, and J. Schultz. 2008. The ITS2 Database II: homology modelling RNA structure for molecular systematics. Nucleic Acids Research 36:D377-380.

Snell, T., D. W. Foltz, and P. W. Sammarco. 1998. Variation in morphology versus conservations of a mitochondrial gene in Montastraea cavernosa (Cnidaria, Scleractinia). Gulf of Mexico Science XVI 2:188-195.

Swart, P. K., A. Saied, and K. Lamb. 2005. Temporal and spatial variation in the $\delta^{15} \mathrm{~N}$ and $\delta^{13} \mathrm{C}$ of coral tissue and zooxanthellae in Montastraea faveolata collected from the Florida reef tract. Limnology and Oceanography 50:10491058.

Thornhill, D. J., T. C. LaJeunesse, and S. R. Santos. 2007. Measuring rDNA diversity in eukaryotic microbial systems: how intragenomic variation, pseudogenes, and PCR artifacts confound biodiversity estimates. Molecular Ecology 16: $5326-5340$.

Todd, P. A. 2008. Morphological plasticity in scleractinian corals. Biological Reviews 83:315-337.

Vermeij, M. J. A., and R. P. M. Bak. 2002. How are coral populations structured by light? Marine light regimes and the distribution of Madracis. Marine Ecology Progress Series 233:105-116.

Wyman, K. D., Z. Dubinsky, J. W. Porter, and P. G. Falkowski. 1987. Light absorption and utilization among hermatypic corals: a study in Jamaica, West Indies. Marine Biology 96:283-292. 